\title{
Research Paper \\ The Impact of Industrial Projects on Empowerment of Local Communities (Case Study: Shazand Refinery)
}

\author{
*Mahmoud Jomepour ${ }^{1}$, Gholamreza Kazemian², Masoumeh Dehghan ${ }^{3}$
}

1. Professor, Department of Social planning, Faculty of Social Sciences, Allameh Tabataba'i University, Tehran, Iran.

2. Assistant Professor, Department of Governmental Management, Faculty of Management \& Accounting, Allameh Tabataba'i University, Tehran, Iran

3. MSc., Department of Social planning, Faculty of Social Sciences, Allameh Tabataba'i University, Tehran, Iran.

Citation: Jomepour, M., Kazemian, Gh., \& Dehghan, M. (2016). The Impact of Industrial Projects on Empowerment of Local Communities (Case Study: Shazand Refinery. Journal of Rural Research. 7(3), 470-485. http://dx.doi.org/10.21859/jjr-07034

dof: : http://dx.doi.org/10.21859/jjr-07034

Received: 11 Apr. 2016 Accepted: 8 Aug. 2016
Keywords:

Shazand refinery,

Empowerment,

Capacity building,

Agency, Opportunity

structure

\begin{abstract}
A B STRACT
Empowerment is one of the new development paradigm components which today is a central concept in the discourse and practices of development. It is a return from top-down planning procedure to bottom-up planning procedure in endogenous development and its approaches. This study intends to evaluate the effects of the oil and gas industry on empowerment in Shazand region. Empowerment is measured in two dimensions: agency and opportunity structure. The indicators of these two dimensions are social capacity, economical capacity, human capacity, ecological capacity, physical capacity and opportunity structure. The research methodology is description and quantitative analysis by using questionnaire. Based on the Cochran formula the sample size is 378 and multi-stage sampling was used. The findings of the study showed the social capacity with an average of 2.51 , the economical capacity with an average of 2.73 and human capacity with an average of 2.49 are on medium level after building refinery. Physical capacity with an average of 2.06, ecological capacity with an average of 1.54 and opportunity structure with an average of 1.98 were extremely undesirable. In general, the empowerment of this region which is affected by Shazand refinery is moderate and downward and far away from desirable level. In other words, the weak interaction between the oil industry and the local community causes the low impact on the local community empowerment.
\end{abstract}

\section{Extended Abstract}

\section{Introduction}

he advent of industrial technologies and $\mathbf{T}$ heavy industries including oil and gas in the communities create changes in the life style of that region. Until a few decades ago, the performances of these industries were examined only by economist, with emphasis on employment and income but recently social consequences of the construction of these industries has attracted the attention of researchers. 1960s was the beginning period for revising the development concepts.
Later the term empowerment pioneered and was accepted by the international development with enthusiasm in 1990s. Since development is a dynamic and sustainable process of increasing the capacity and empowering communities and changes and improvements to improve the lives of people, this research with assessment of social impact of Shazand refinery aimed to study the impact of this industry on local communities' empowerment.

\section{Methodology}

Due to the multi-dimensional nature of the concept of empowerment and its usage in different fields such as management, psychology, geography, agriculture, sociology and

\section{* Corresponding Author:}

Mahmoud Jomepour, PhD

Address: Department of Social Welfare Planning, Faculty of Social Sciences, Allameh Tabataba'i University, Tehran, Iran.

Tel: +98 (912) 2203429

E-mail: mahjom43@gmail.com 
other fields, it has got several meanings. In this study, empowerment is enhancing an individual's or group's capacity to make choices and transform those choices into desired actions and outcomes which is examined by two dimensions: agency and opportunity structure. Agency is defined as an ability of an actor for meaningful choices. Capacitates are constructor dimensions of agency which in this research is assessed by the indicators of social capacity, economic capacity, human capacity, ecological capacity, physical capacity. Agency cannot be considered as an empowerment by itself so another dimension of empowerment that is considered is opportunities structure, which is including formal and informal institutions that an actor acts in it. This study is descriptive and qualitative method and questionnaire tool has been used in it. The study population consisted of all residents of Kazaz, Ghadamgah, Jamal Abad, Akbar Abad (as a rural community) and Shazand city (as an urban community) and according to the Cochran formula the sample size was estimated to be 367 and sampling method is multi-stage cluster.

\section{Results}

Research findings show that after building the refinery, social capacity with a mean of 2.51 , economic capacity with a mean of 2.73 and human capacity with a mean of 2.49 are at average level and physical capacity with a mean of 2.06, ecological capacity with a mean of 1.54 and opportunities structure with a mean of 1.98 are on very weak and undesirable level. The total degree of empowerment in communities affected by refinery is moderate to low and is very far away desired level; so it can be stated that the construction and operation of Shazand refinery only could partly empowered target population in terms of social capacity, economic capacity and human capacity but has destroyed existing ecological capacity, also physical capacity and the opportunities structure are not in favorable conditions. In order to know the existence of differences between dimensions of empowerment, ranking and comparing these aspects with each other, the Friedman test was used. The results show that the average rank calculated for social capacity is 4.32 , human capacity 4.15 , economic capacity 4.23 , physical capacity 3.39 , ecological capacity 2.48 and opportunity structure 2.43 .

\section{Discussion}

In general, it can be said that, starting of development projects in Shazand have improved people's economic life and indications of this improvement can be seen in lifestyles, availability of facilities and restoration of urban space but this project has not created an opportunity structure for its host community and just improved agency dimension partially and poorly. According to the Alsop and Heinson theory, as long as there is not any potential context for the agency, empowerment will not happen. In the other words, lack of an organic relationship between the oil industry and the local community caused less effect on the local community empowerment. To solve issues and challenges caused by the refinery and also along communities' empowerment three proposals have been suggested: 1. Establishment and strengthening of downstream industries; with the launch of petrochemical downstream industries Sustainable output and employment growth would achieved in this area. So by employment generation, these industries would help people in the regional and the national levels. 2. Conducting training programs in the area towards the oil and gas and chemical industries. The establishment of the Petrochemical technical school, chemical and pharmaceutical industries and pushing students to study in the fields related to the these industries causes natives to be equipped with the knowledge related to these activities. 3. Environmental investigation about the destructive effects of refinery pollutions. Official reports, research and scientific experiments in this regard, in addition to elimination of existing concerns, would remind the importance of a healthy life for citizens living in the region to the authorities

\section{Conclusion}

Finally, we can discuss the impacts of industrial projects of Shazand Refinery on the empowerment of local communities. In general, starting of development projects in Shazand improved people's economic situation and this improvement can be seen in their lifestyles, availability of facilities, and restoration of urban space. However, this projects did not create an opportunity for its host community and just partially and very poorly improved agency dimensions. According to Alsop and Heinsohn Theory, if there is not any potential context for the agency, empowerment will not happen. In other words, lack of an organic relationship between the oil industry and the local community nullifies any effect on the local community empowerment. The total amount of empowerment in communities affected by refinery is moderate to low and far away from desired level. 


\title{
تأثيرات يُروزههاى صنعتى بر توانمندسازى جوامع محلى (مطالعه موردى: يالايشكاه شازند)
}

\author{
"محمود جمعهيور'، غلامرضا كاظميان'، معصومه دهقانى"

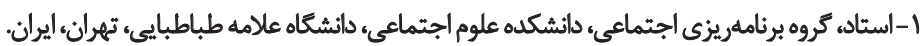

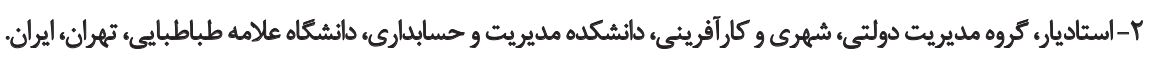

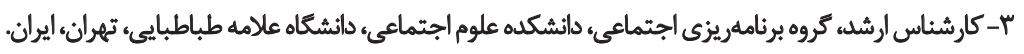

\begin{abstract}
حكיט
تاريخ دريافت: بr فروردين هوش

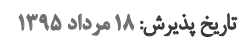

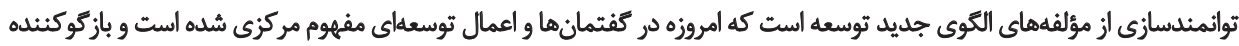

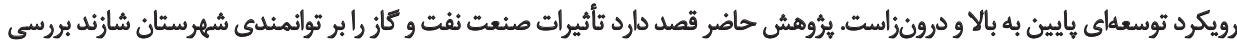

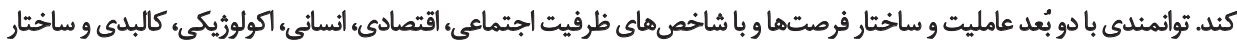

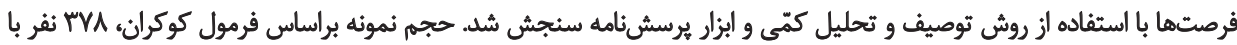

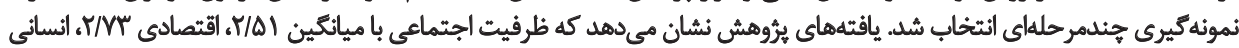

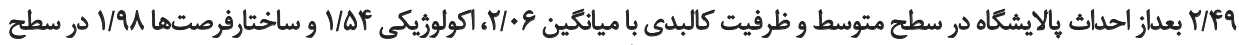

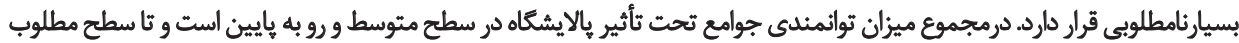

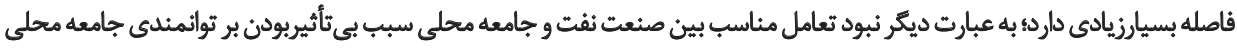

كليدواثرهها:

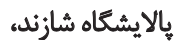

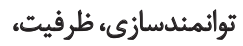
عامليت، ساختار فرصت
\end{abstract}

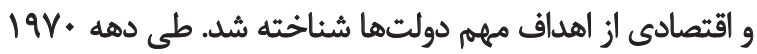

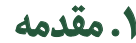

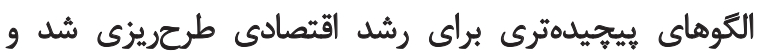

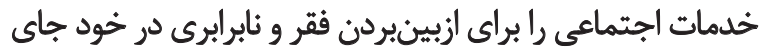

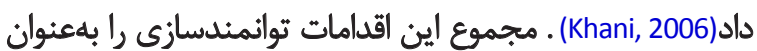
رويكردى مناسب براى فقرزدايى مطرح كرد.

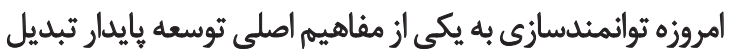

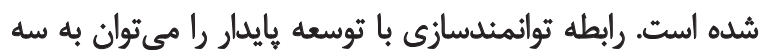

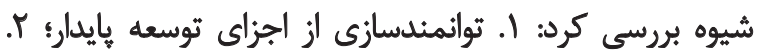

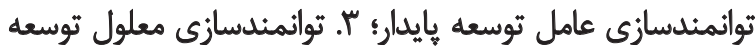

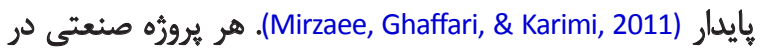

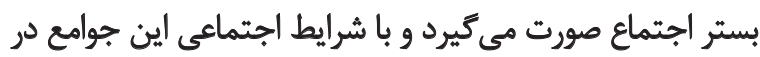

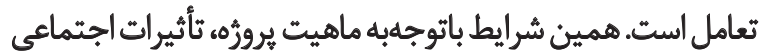

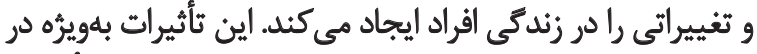

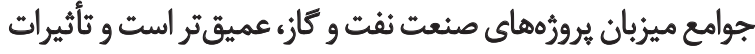

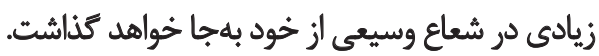

"الايشگاه امام خمينى شازندواقع در استان مركزى و شهرستان شازند يكى از نُه يالايشًاه احداثشده در ايران و و جديدترينان مركين

نديده بارز و مشخص كشورهاى در حال توسعله، افزايش

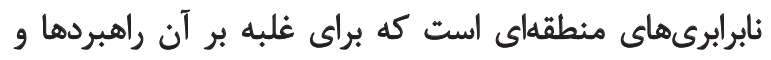

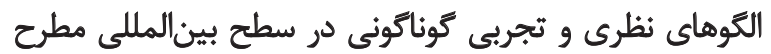

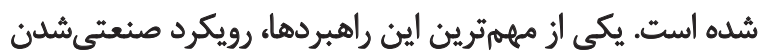

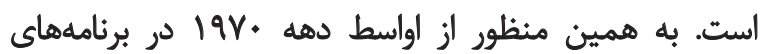

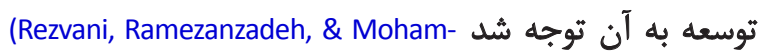

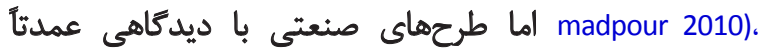

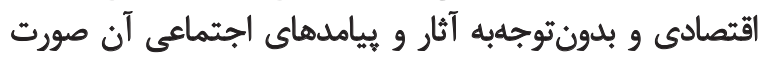

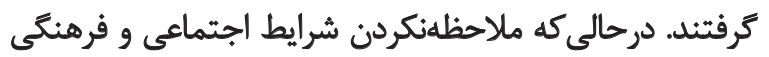

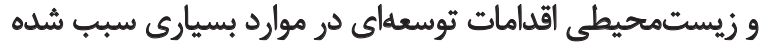

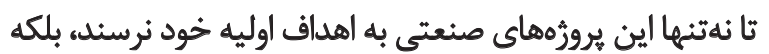

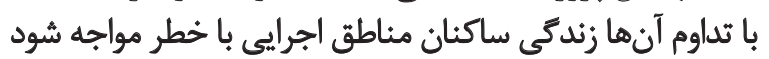
.(Talebian \& Omrani Majd, 2008)

از سويى در دها •199 كه دوره بازنترى در مفاهيم توسعه

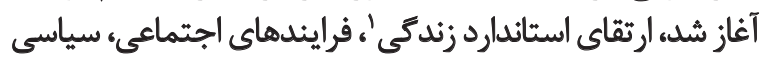

1. Improved living standards 
عوامل در توانمثدسازى روستايي بهشمار ميآرود. والرشتاين

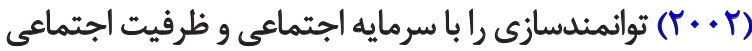

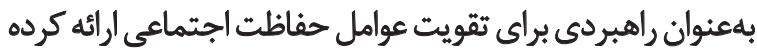

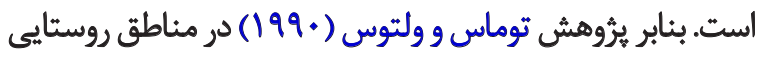

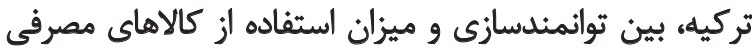

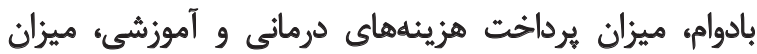

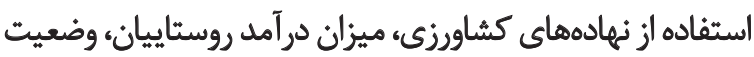

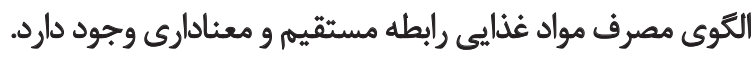

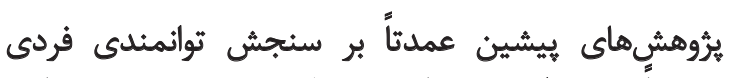

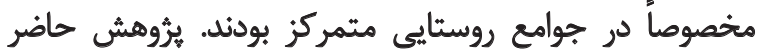

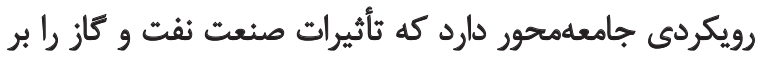

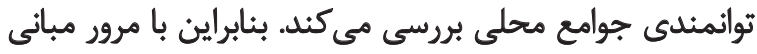

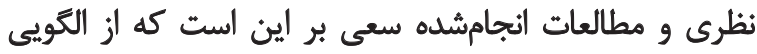

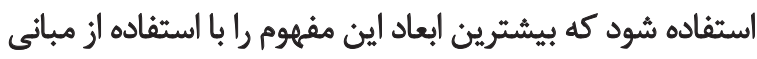
نظرى و ادبيات يرؤهشى و تحقيقات بيشين، يوشش دهان دهد.

$$
\text { مبانى نظرى و مغهومى تحقيق }
$$

ريشه اصطلاح توانمندى راكه بر فلسفه اين مفهوم اثر كذاشته

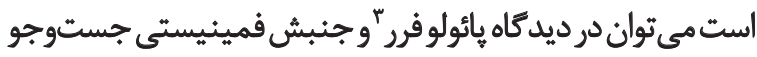

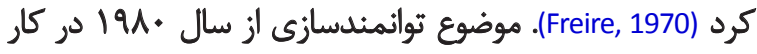

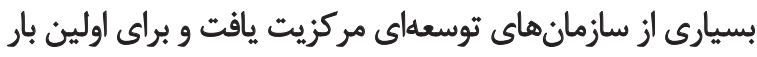

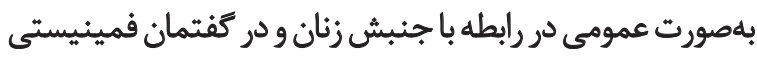

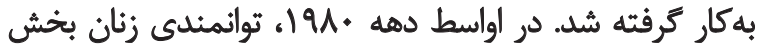

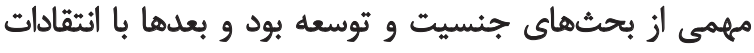

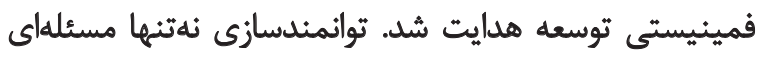

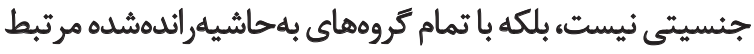

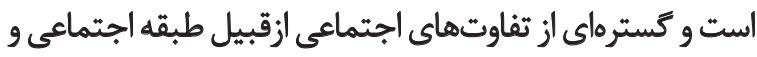

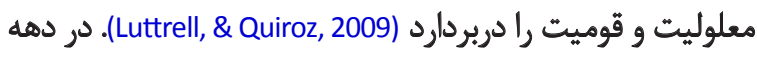

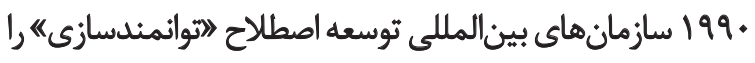

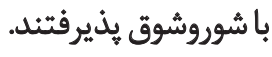

از توانمندى تعاريف متفاوتى بيان شده است. بعضى بر منابع

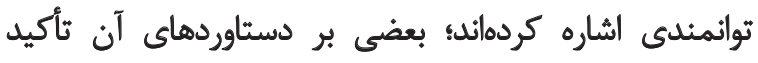

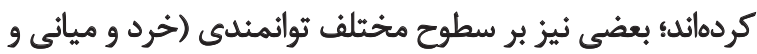

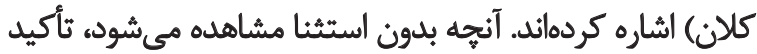

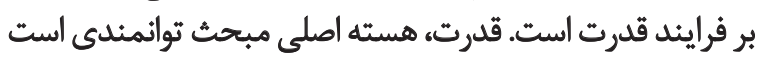
كه در ترجمه واره حذف شده و توانمندى بلجاي آن آمده است. توانميندى فرايند

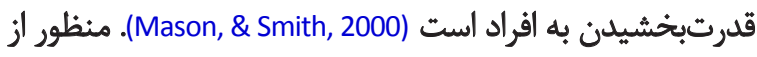

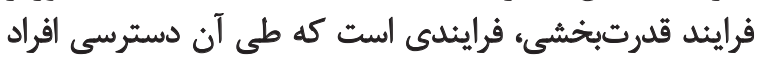

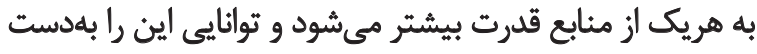
مى آوردند كه از امكانات و ابزارهاى موجود براي بهيبود وضعيت
و مجهزترين در سطح منطقه است كه در زمينى به مساحت

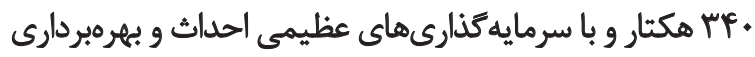

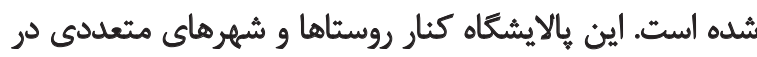

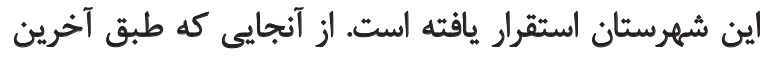

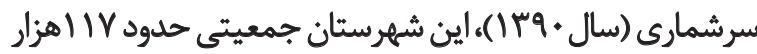

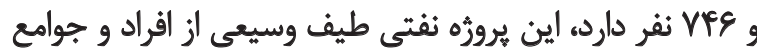

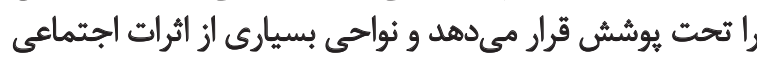

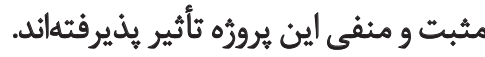

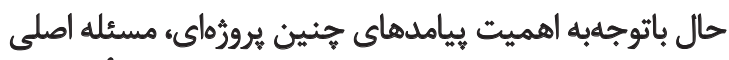

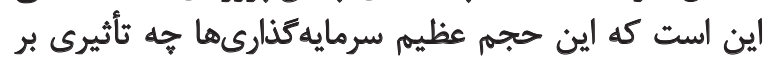

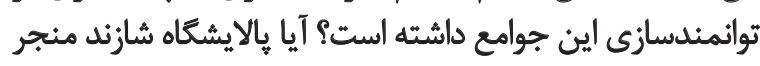

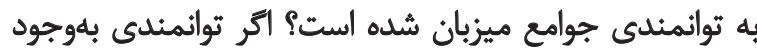
آمده، جهه ابعادى را دربرداشته است؟ ميزئ

\section{ب. مرورى بر ادبيات موضوع}

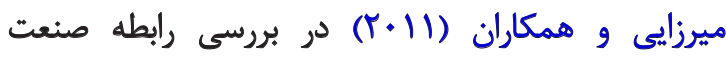

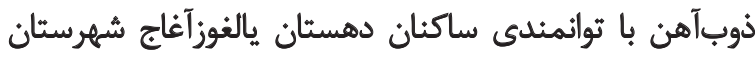

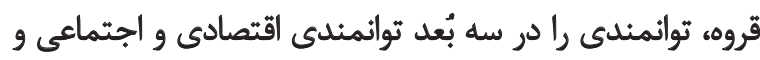

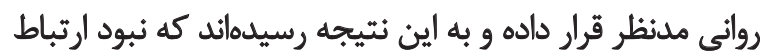

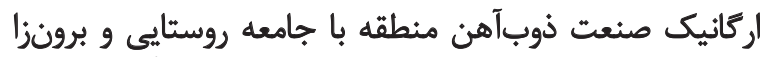

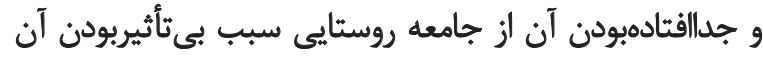

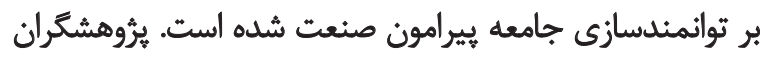
به دنبال سنجش توانمندى (اقتصادى) شالى كاران شهرستان

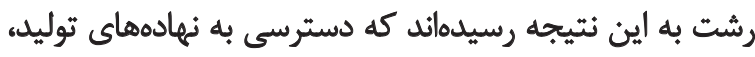

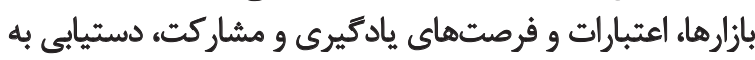

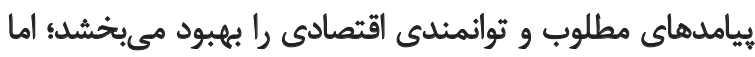

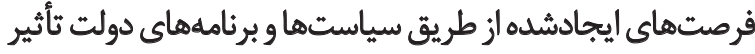

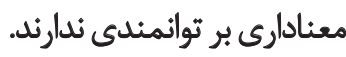

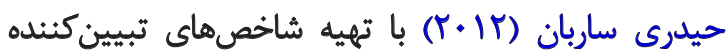

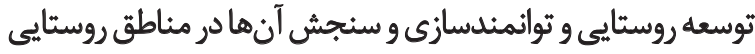

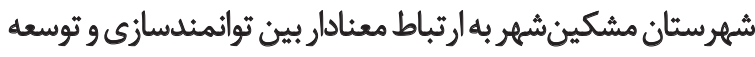

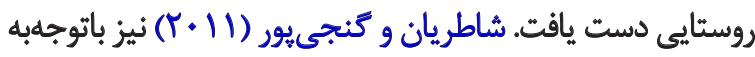

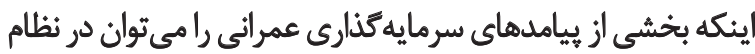

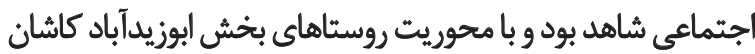

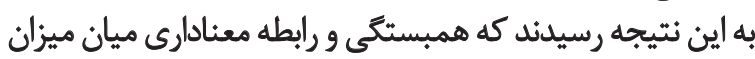

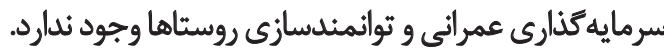

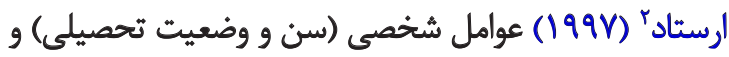

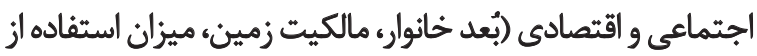

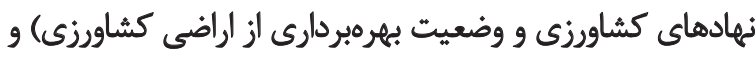

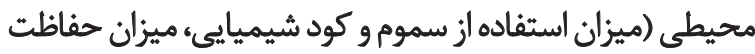

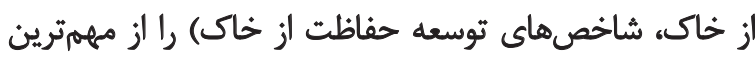


توانمندسازى بهعنوان تغيير در روابط قدرت تعريف شده است.

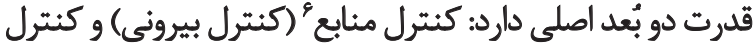

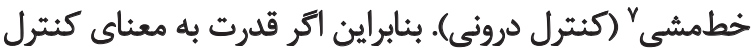

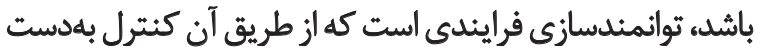

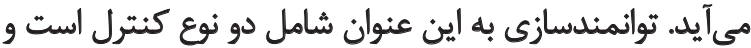
بلهدرت بدون اين دو ممكن است (Sen, 1997). توانمندسازى جوامع هموارهتحت تأثير سياستهاو رويكر دهاى

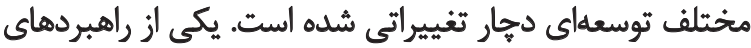

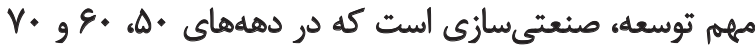

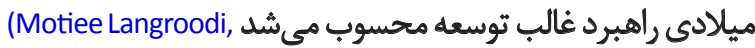
و Najafi Kani, 2006)

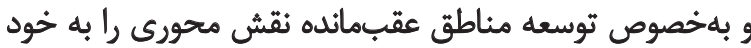

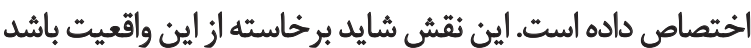

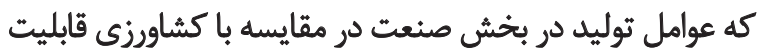

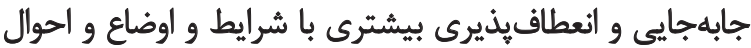

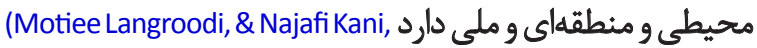

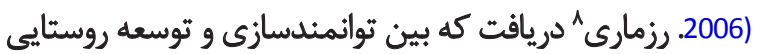

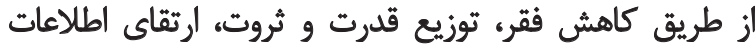

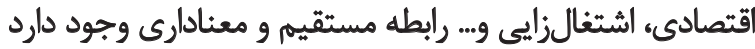

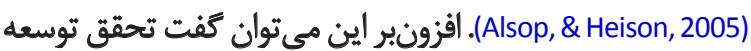
روستايى تا حدودى ناشى از توانمندسازى روستاييان است. با استفاده از جهارهوبى كه آلسوب و هينسون درباره

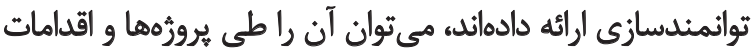

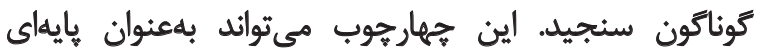

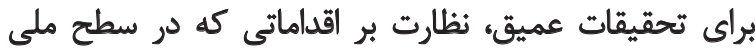

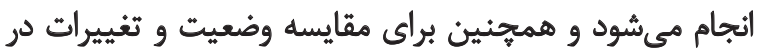

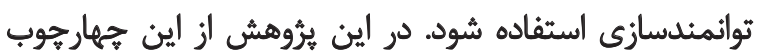

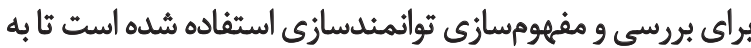

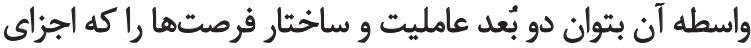

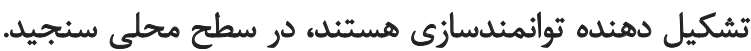

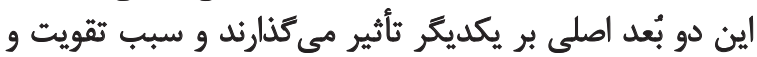
افزايش يكديكر مىشوند (Alsop, \& Heison, 2005).

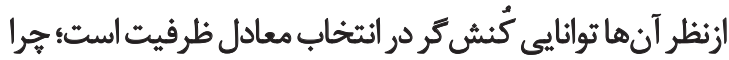

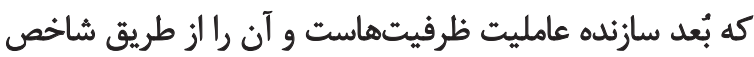

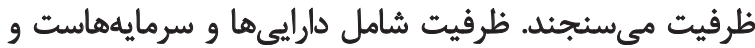

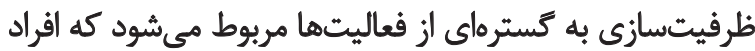

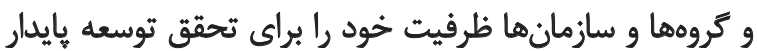

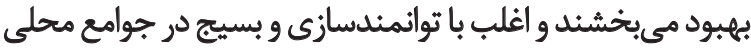
مرتبط است (Peeters, \& Ateljevic, 2009).

6. Resource control

7. Ideology control

8. Rosemary
خود و جوامع استفاده كنئد.

امروزه توانمندى مفهوم مركزى در كفتمانها و و اعمال

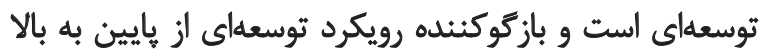

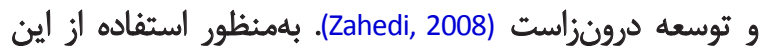

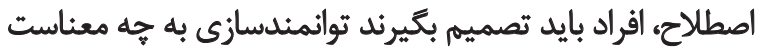

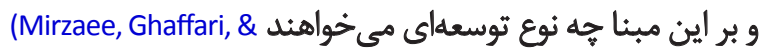

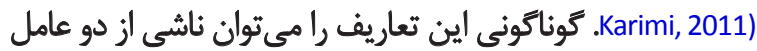

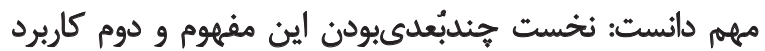

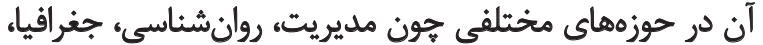
كشاوزىى، جامعهشناسى (Mirzaee, et al., 2011).

ديدكّاه ها ونظريه هاى توانمندى

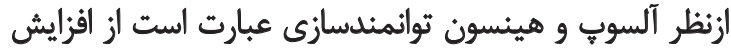

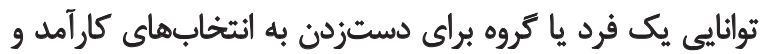

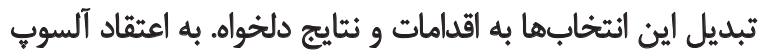

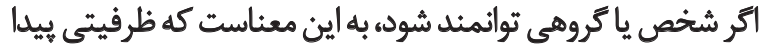

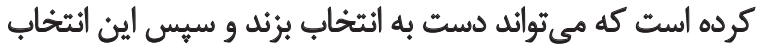

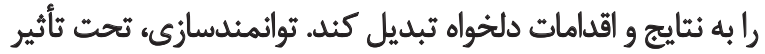
دو عامل است: عامليت و ساختار فرصت (Alsop, \& Heison, 2005). يكى ديكر از صاحبنظران اصلى و مهم در توانمندسازى كبير

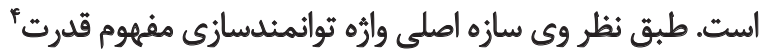

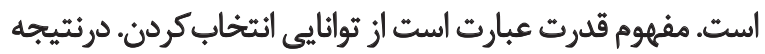

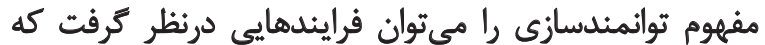

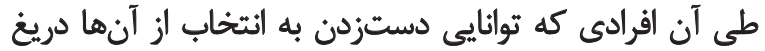

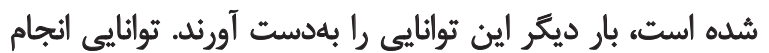

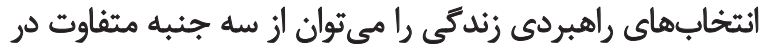

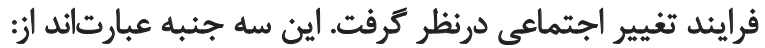
منابع و عامليت و دستاوردها (kabeer, 2005).

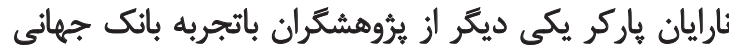

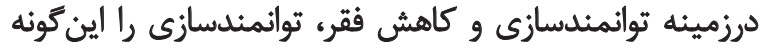

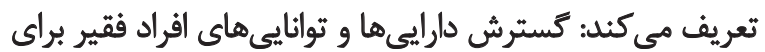

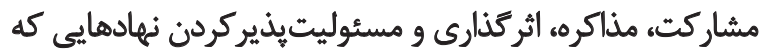

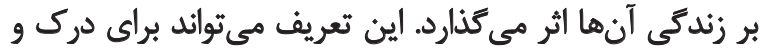

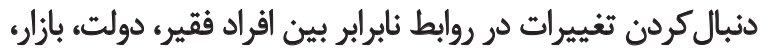

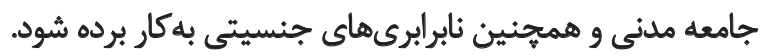

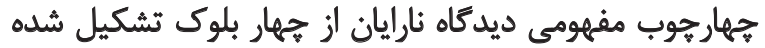

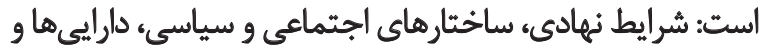
توانايىهاى فردى و جمعى افراد فقير (Narayan, 2002).

سن نيز نظريه جالبى در مورد توانمندسازى بر هايه كار سريلاتيها باتليوالاه | ارائه داده است كه بر مفهوم توانمندسازى متمركز است.

4. Empower

5. Srilatha Batliwala 


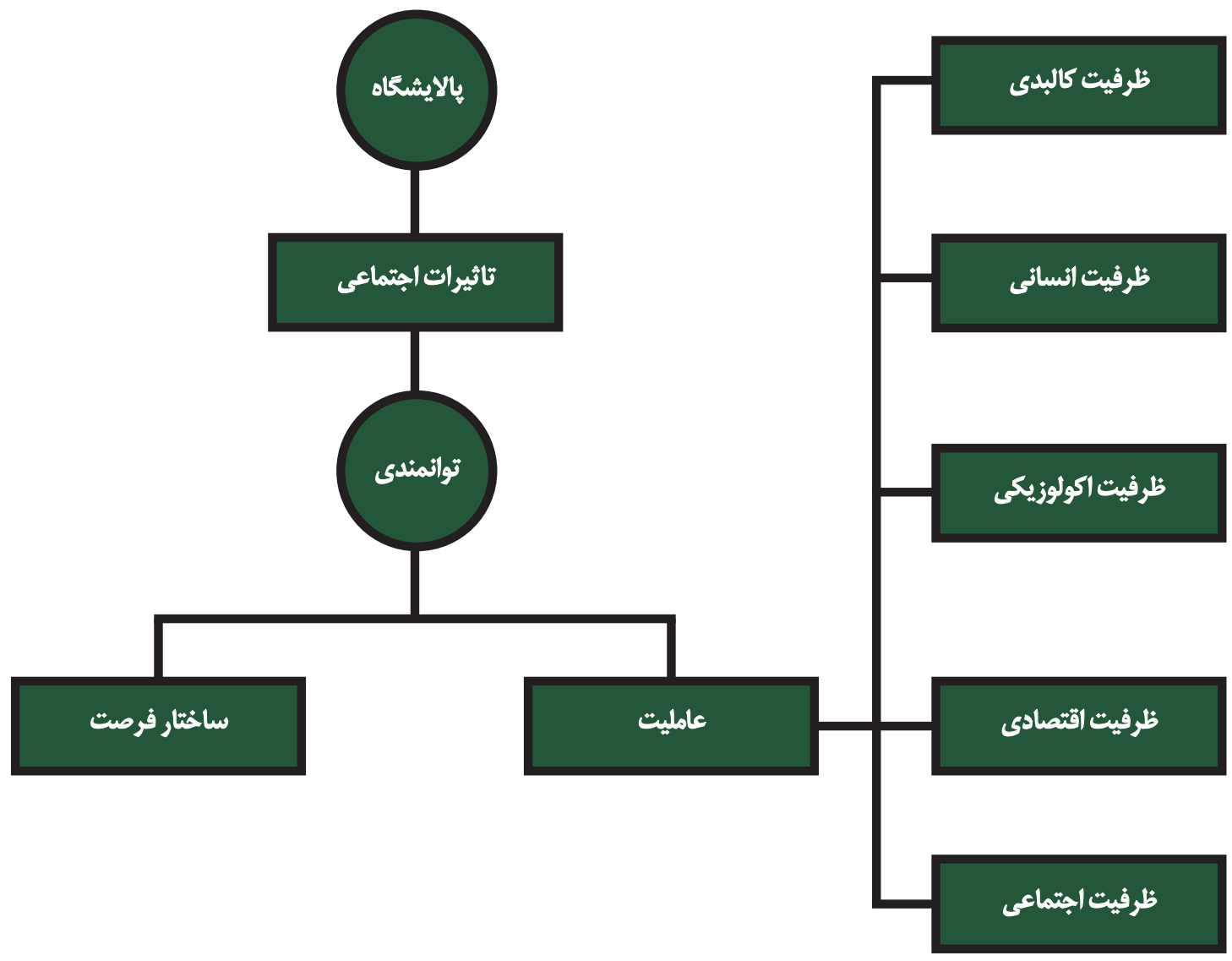

و ينجهم را تشكيل مى دهند كه در مدل نظرى ثيروهش قابل مشاهده

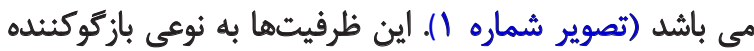
سرمايهها و دارايى هاى افراد در آن حيطهها هستند.

عامليت بهتنهايى نمىتواند مترادف توانمندسازى درنظر

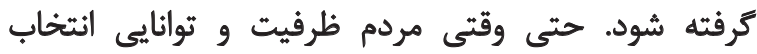

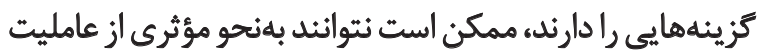

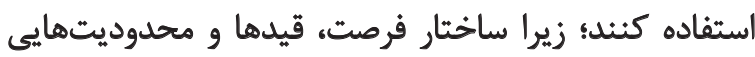

در تمام مدلهايى كه ظرفيتسازى أندازهيرى شدهاه، سه بُعد

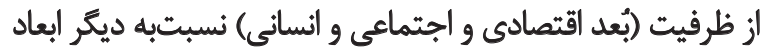

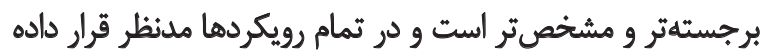

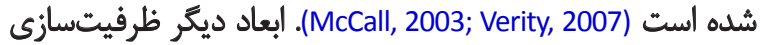

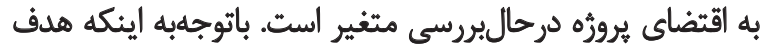

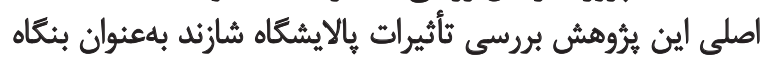

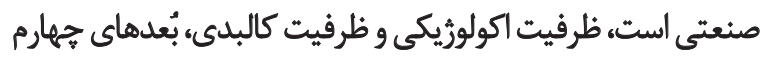

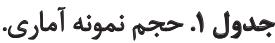

\begin{tabular}{|c|c|c|c|}
\hline درصد & تعداد & \multicolumn{2}{|c|}{ شهر/آبادى } \\
\hline$v \Delta \%$ & TAS & شهر شازند & جامعه شهرى \\
\hline$\wedge \%$ & rq & آبادى كزاز & \\
\hline A $\%$ & r. & آبادى قدمكاه & \\
\hline v\% & ro & آبادى اكبرآباد & جامعه روستايى \\
\hline$r \%$ & 9 & آبادى جمال آباد & \\
\hline $1 .+\%$ & $\mathrm{rA}$ & جمع & \\
\hline
\end{tabular}


جدول ז. ابعاد، شاخصها و مؤلفههاى توانمئدسازى.

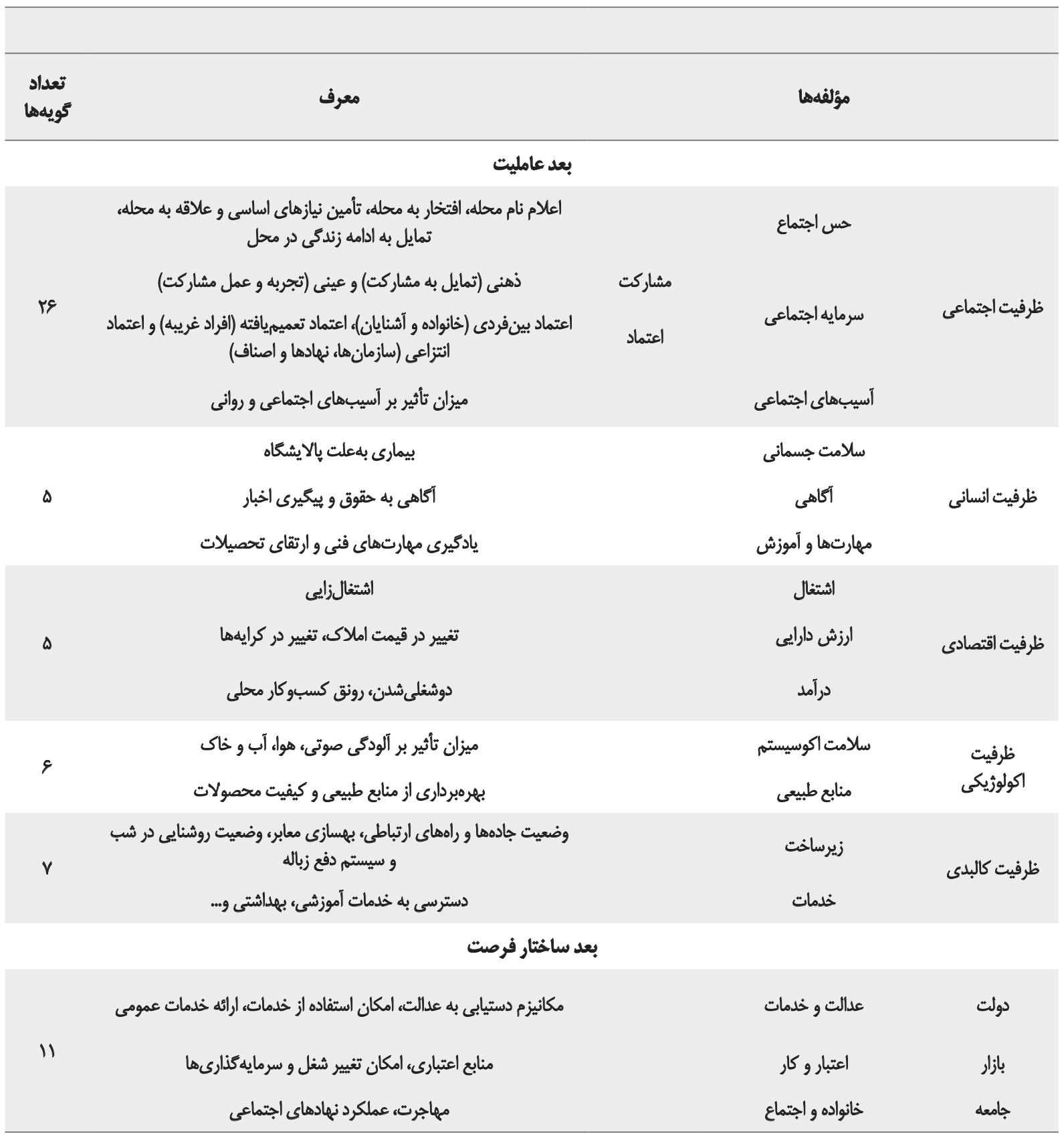

\section{每}

فرصت را براي جوامع محلى ئيرامون خود فراهم ساخته

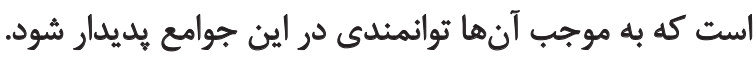

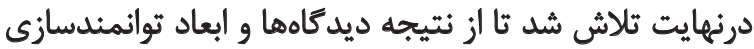
و ظرفيتسازى مدل نظرى زير ترسيم شود.

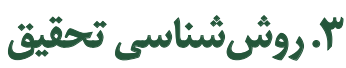
يُروهش حاضر از نوع توصيفىاكتشافى است كه در آن روش
را بر آنها اعمال مى كند. بُعد ديكرى از توائمندى كه در

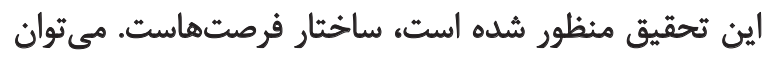

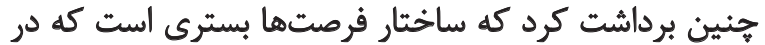

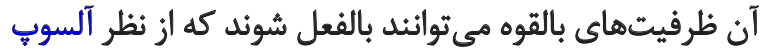

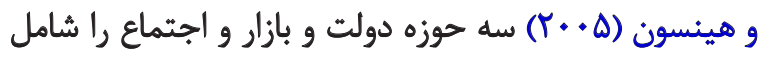

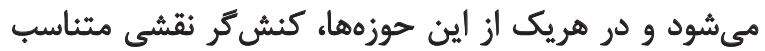

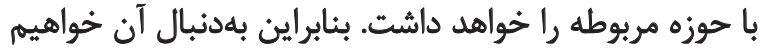

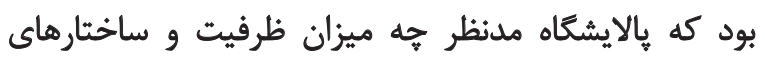


جدول لَ. وضعيث معرفهاي حس اجتماع.

\begin{tabular}{|c|c|c|}
\hline 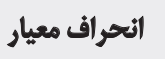 & مياتكين & Ladئ \\
\hline$M / M$ & $1 / 89$ & من فكر مى كنم بعلاز احلاث يالايشكاه ديكر محل سكونت ما جاى خوبى براى زندكى كردن نيست." \\
\hline .1910 & 1/9. & بعلاز احداث يالايشكاه ثياز هاي اساسى من در شهر ثامين هي شود. \\
\hline $1 / M T M$ & $r / T V$ & به ادامه زئدكى در اين محل تمايل زيادى دارم. \\
\hline $1 / M V A$ & $r / \mathcal{H}$ & بهدليل وجود يالايشكاه با اقتختار نام شهر را اعلام هي كنم. \\
\hline vire & $t / T F$ & از زندكى كردن در اينجا للث ميبرم. \\
\hline
\end{tabular}

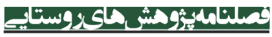

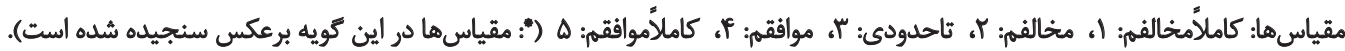

حاضر برمبناى آن يىريزى شده است، براى سنجش در جامعه

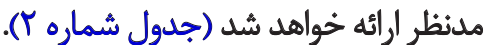

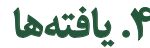

سيماي باسخدهندُّان

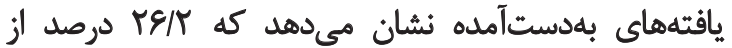

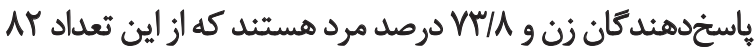

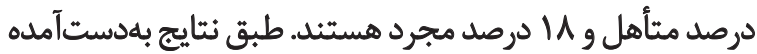

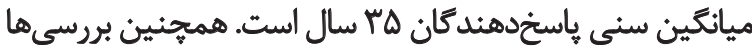

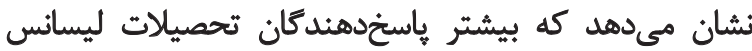

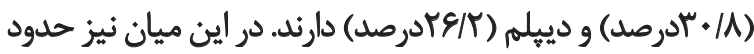

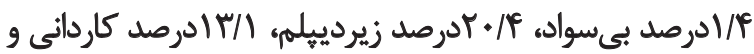
دم/NT

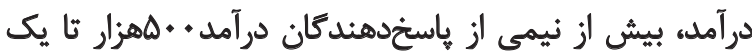

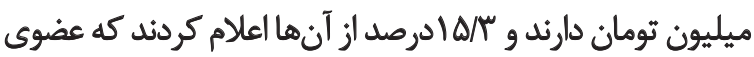

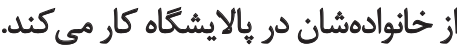

وضعيث توانمئدى

تجزيهوتحليل مفهوم توانمندي از بين متّفيرها قابل بررسي

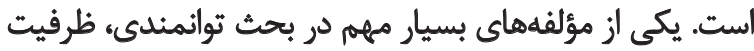

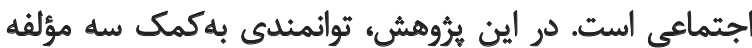

يُيمايش و ابزار برسشنامه به كار كرفته شده است. جامعه آمارى

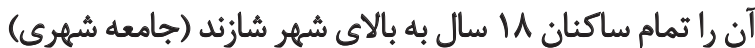

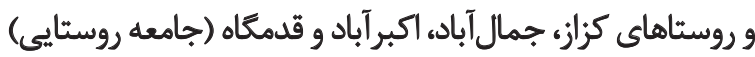

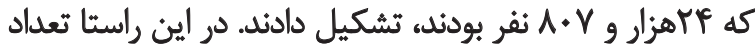

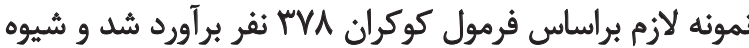

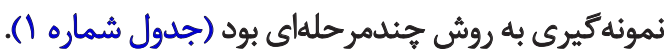
در اين بئوهش دو نوع اعتبار صورى و ساز الى مدنظر قرار كرفت.

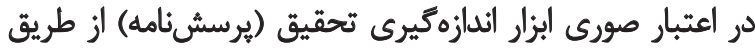

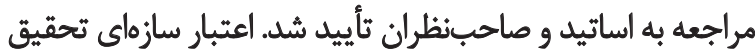

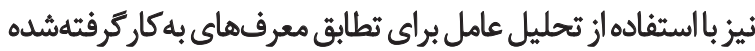

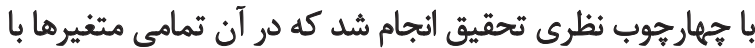

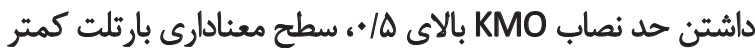

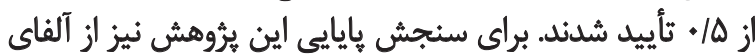

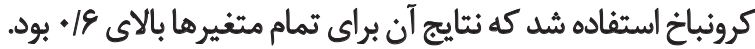

$$
\text { تثريف عملياتئي }
$$

در اين تحقيق فقط يك متغير درنظر كرفته شده است؛ متغير

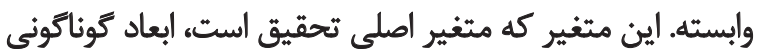

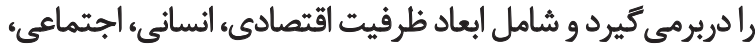

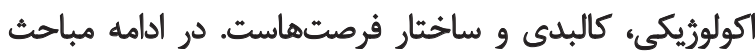

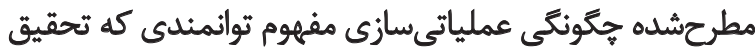

جدول F. وضعيت معرفهاى مشاركت.

\begin{tabular}{|c|c|c|}
\hline انحراف معيار & مياتكَين & lods \\
\hline$M / P M$ & $\mathrm{~T} / \mathrm{KA}$ & تمايل براى صحبت كردن با مسئولان شهر درباره مسائل و مشكلات ناشى از يالايشكاه. \\
\hline I/TAS & $r / M r$ & اعتقاد به تأثيركذارى بيشتر همكارى بين اهالى شهر تا كار فردى. \\
\hline V/Dr & $M / M F$ & نوشتن نامه و ثماس اعتراضى با مسئولان شهر درباره مشكلات محل سكونت خود كه از هالايشكاه ناشى مىشود. \\
\hline$|/ 4 I|$ & r & مشورت با الهالى شهر درباره مشكلات بهوجودآلمده. \\
\hline
\end{tabular}


جدول ه. وضعيت معرفهاي اعتماد.

\begin{tabular}{|c|c|c|}
\hline انحراف معيار & مياكين & S \\
\hline $1 /+49$ & $r / r \Delta$ & شهردارى \\
\hline l/Irs & $r / \varphi$. & امام جماعت \\
\hline.$/ 94$ & ( & اخبار هحلى \\
\hline.$/ 9 \Delta \Delta$ & $T / / Q$ & شوراى حل اختلاف \\
\hline $1 /+80$ & r/Tq & شوراى اسلامى \\
\hline $1 / / V^{4}$ & $r / \mu$ & يليس \\
\hline$y \cdot r v$ & $|/ A|$ & نماينده شازند \\
\hline . /A94 & $I / N$ & هسئولان يالايشكاه \\
\hline $1 / / V w$ & $m / M$ & خانواده، آشئايان و... \\
\hline$y+\Delta F$ & $|/ \lambda|$ & افراد غريبه و مهاجران \\
\hline
\end{tabular}

اندازهميرى شده است: مؤلفه حس اجتماع و سرمايه اجتماعى (باعباع مشاركت

نتايج حاصل از بررسى وضعيث مشاركت بيانكر آن است كه

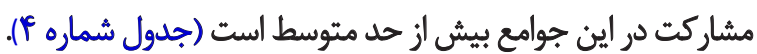

shel

ميزان اعتماد در جوامع بررسىشده بايين و نامطلوب است.

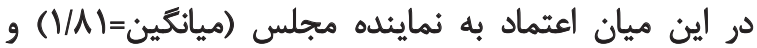

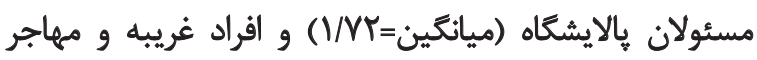

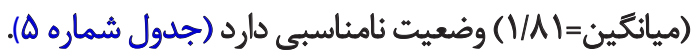

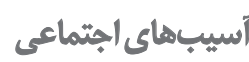

جدول شماره \& نشاندهنده نظر باسخدهندكان در رابطه با

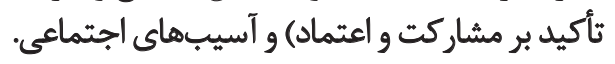
حس اجتماع بايينتر از حد متوسط است. ههمترين عاملي كأله

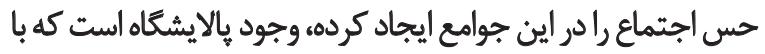

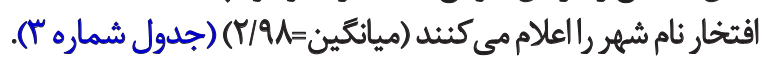

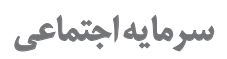
در ادبيات سرمايه اجتماعي صاحبنظران اعتماد و مشاركت و وانقان

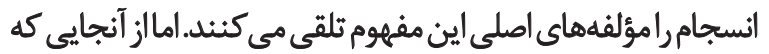

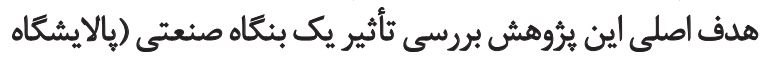

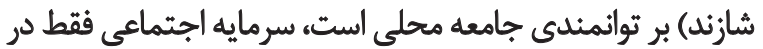

\begin{tabular}{|c|c|c|}
\hline انحراف معيار & مياتكين & Lodis \\
\hline I/MT. & $T / W$ & سرقت و دزدى \\
\hline I/Tra & $r / \Delta r$ & اعتياد \\
\hline I/TOY & $r / M$ & قاجاق مواد مخدر \\
\hline I/TEA & $r / M r$ & دعوا و دركيرى در محل \\
\hline IMIO & r/er & اختاذى وزوركيرى \\
\hline I/TIQ & $1 / 9 f$ & الحساس نابرابرى و ضايعشلن حقوق \\
\hline ITET & T/AA & احساس نالمنى بهدليل وجود اشرار و... \\
\hline
\end{tabular}

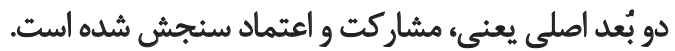

جدول ؤ وضعيت معرفهاى آسيبهاى اجتماعى. 
جدول 9. وضعيت معرفهاي ظرفيت اقتصادى.

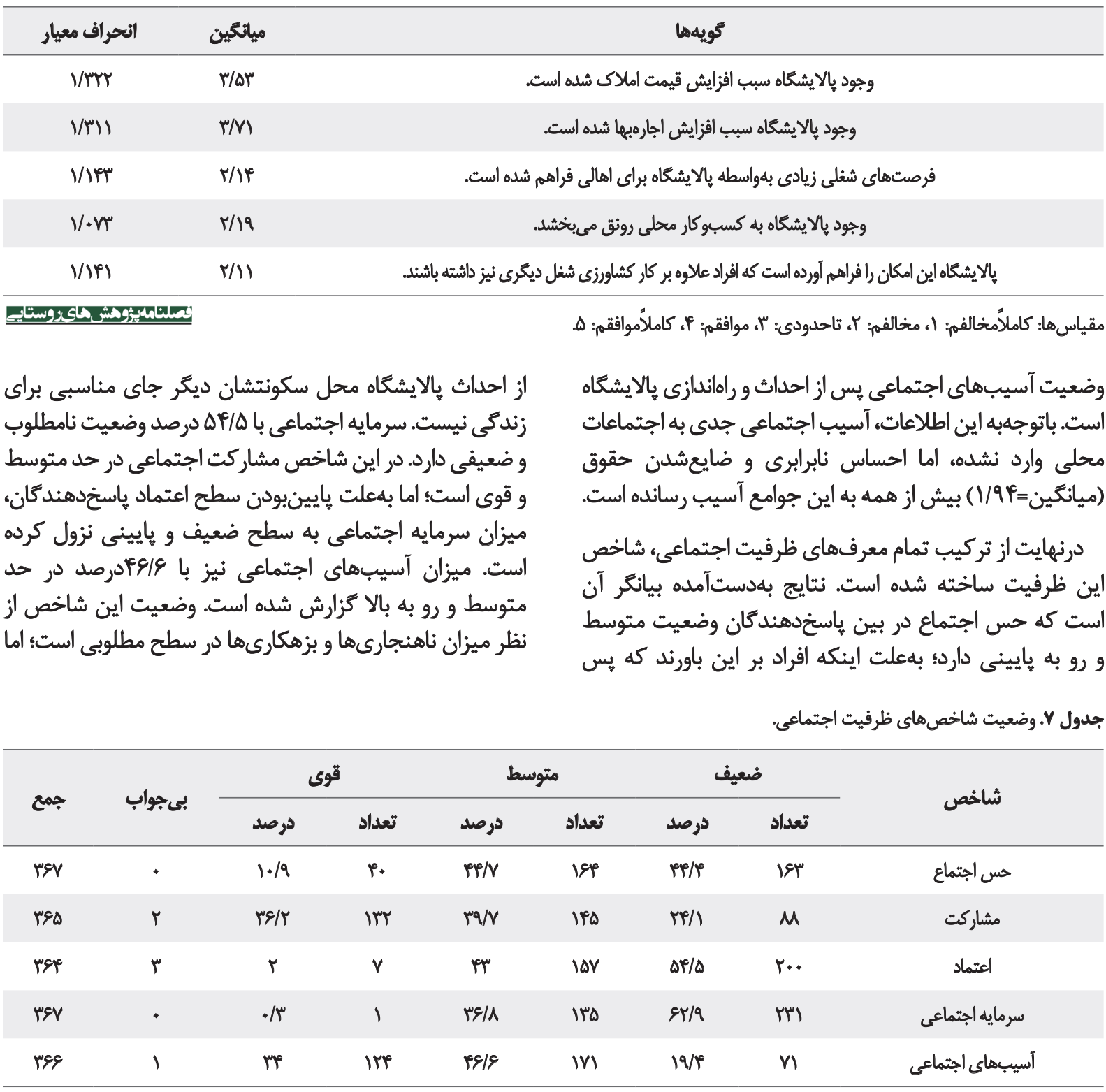

\section{تملمان}

جدول A. وضعيت معرفهاي ظرفيت انساني.

\begin{tabular}{|c|c|c|}
\hline انحراف معيار & 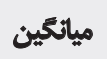 & lods \\
\hline $1 / T \Delta$ & $r / r$ & اهالمي به حقوق خود در قبال احداث يالايشكاه در نزديكى محل سكوتثشان آكاهي يافتهاند. \\
\hline $1 / 101$ & r/af & الهالى اخبار مربوط به بالايشكاه و مشكلات ناشى از آن رادر روستا ييكيرى مى كنثد. \\
\hline $1 / m$ & r/TA & افراد براى بهدست آوردن شغل در بالايشكاه تحصيلات خود را افزايش مى دهند. \\
\hline I/MFE & T/VG & افراد محلى به واسطه وجود هالايشكاه مهارتهاى فئى و... بهدست آوردهاند. \\
\hline.$/ 9 y^{n}$ & $V / \Delta \Delta$ & در اطرافم كسائي را مي شناسم كه علت بيماري شان، آلايندكى يالايشكاه بوده است. \\
\hline
\end{tabular}


جدول •1. وضعيت معرفهاى ظرفيت اكولوريكى

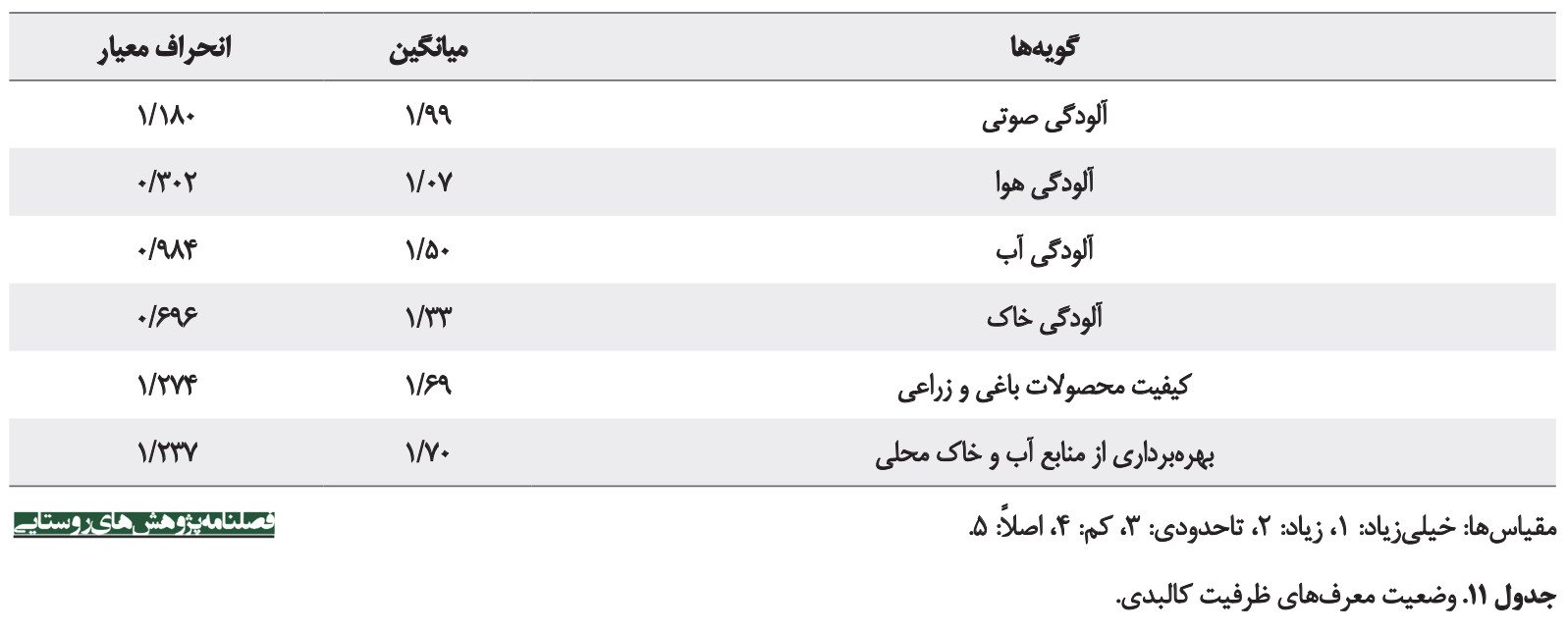

\begin{tabular}{|c|c|c|}
\hline انحراف معيار & 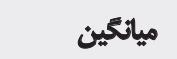 & كائها \\
\hline War & threV & بهبود وضعيث جادهها در داخل روستا (آسفالت و...) \\
\hline WIT & $r / T \Delta$ & بهبود وضعيت راههاى ارتباطي يين روستاها و شهرهاى مختلف \\
\hline $1 / r^{\infty}$ & $r / \pi$ & عوايدى از يالايشكاه صرف بهسازى معابر، سامائهاى دفع زباله و هنين كارهاى شده است. \\
\hline.$/ 981$ & V/Fa & دسترسي به خلمات أموزشى مثل كلاس هاى أموزشى مختلف \\
\hline.$/ 94$ & IVA & دسترسى به خدمات فرهنكى و ورزشى مثل سالن ورزشى، مجتمع فرهنكى و... \\
\hline$M+r$ & $r / r$ & دسترسى به خدمات بهداشتى مثل خانه بهداشت و ... \\
\hline .1998 & IM & دسترسى به وسايل نقليه عمومى و خصوصى مثل اتوبوس و تاكسى \\
\hline 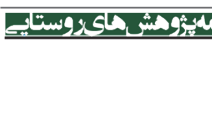 & 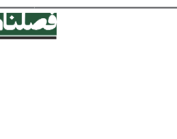 & 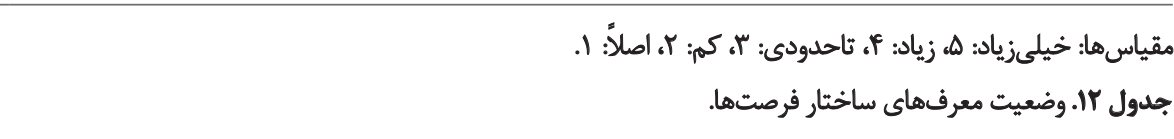 \\
\hline انحراف معيار & ميائكين & كويهذها \\
\hline$V \cdot P r$ & $1 / 8$. & هطرحكردن مشكلات با مسئولان بي فايله است؛ زيرا توجه جندانى به تقاضاها و منافع و مشكلات مردم محلى ندارئل." \\
\hline $1 / \cdots 1$ & $1 / 99$ & مرجعى براى رسيدكى به شكايات مردمى از بالايشكاه وجود ندارد." \\
\hline$r / \Delta V{ }^{\prime}$ & r/DF & دسترسى به روزنامهها و اخبار محلى و مرتبط با مسائل جارى در يالايشكاه و روستا به راحتى امكانئير است. \\
\hline $1 / / \wedge$. & $r / 4 \cdot$ & امكان استفاده از خدمات أموزشى، فرهنكى، بهيداشتى و... براى من وجود ندارد." \\
\hline $1 / \cdot 19$ & $r / \mu$ & از زمانى كه بالايشكاه به اين محل آمده است، تعداد سرمايهكذارى ها در اين هحل افزايش يافته است. \\
\hline $1 / . \Delta 9$ & $1 / \wedge 1$ & صندوق هاى قرضالحسنه تسهيلات بانكى و منابع اعتبارى كوناكونى براى هردم تدارى ديده شده است. \\
\hline.$/ 914$ & $1 / \Delta \Lambda$ & استخدام در هالايشكاه فقط درصورت داثشن آشنا در أن و سفارش شلن توسط كسى امكانيذير است." \\
\hline$\cdot / \Lambda 9 Y$ & 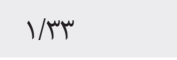 & افراد بهراحتى مى توائند شئل خود را تغيير داده و شغل ديكرى را ايتخاب كنند. \\
\hline $1 / \cdot$ & $1 / 9 \Lambda$ & با ورود صنعت به شهرستان شازئد، از ميزان مهاجرت از اين شهرستان (شهرها و روستاها) كاسته شده است. \\
\hline 1/Trt & $r / \mu$ & نهادهاي اتثظامى در برخورد با سارقان، فروشندكان مواد مخحدر و خاطيان عملكرد خوبى دارند. \\
\hline $1 / r \Delta F$ & $r / M$ & بلراحتى و بلدون دردسر مي تواثم از وامهاي فانكي استفاده كنم. \\
\hline
\end{tabular}

\section{تصلمبن}

مقياس ها: كاملأمخالف م: ا، مخالفم: r، تاحدودى: rا، موافقم: F، كاملأموافقم: ه (": در اين كويه مقياسها برعكس سنجيده شده است). 
جدول سا. نتايج آزمون كايىاسكوئر تكمتغيره بين شاخصهاى توائمندى.

\begin{tabular}{|c|c|c|}
\hline مياتكين & كايلسكوثر & شاخص هاى تواتمندى \\
\hline$r / \Delta 1$ & $\begin{array}{l}X^{r}=V / * r \\
S=\star / *\end{array}$ & ظرفيت اجتماعى \\
\hline$r / 4 q$ & $\begin{array}{c}X^{r}=\varphi \Delta / q 1 \\
S=\star 1 *\end{array}$ & 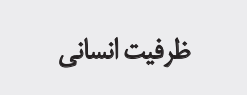 \\
\hline$r / N^{\infty}$ & $\begin{array}{c}X^{r}=e \% / r \\
S=* 1 \ldots\end{array}$ & ظرفيت اقتصادى \\
\hline V/AF & $\begin{array}{l}X^{r}=r / q . \\
S=\star 1 \cdots\end{array}$ & ظرفيت اكولوزيكى \\
\hline$Y / .8$ & $\begin{array}{l}X^{r}=q \Delta / M \\
S=* 1 \cdots\end{array}$ & ظرفيت كالبدى \\
\hline $1 / 4$ & $\begin{array}{l}X^{r}=r / I r \\
S=* / .\end{array}$ & ساختار فرصتها \\
\hline
\end{tabular}

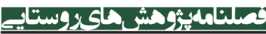

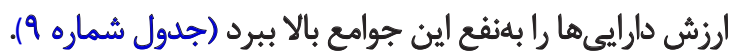

$$
\text { ظرفيت اكولوزيكي }
$$

وضعيت ظرفيت اكولوزيكى منطقه هايينتر از حد متوسط است

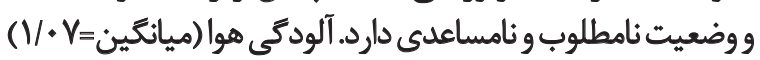

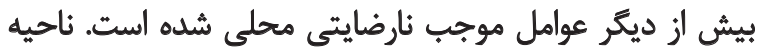

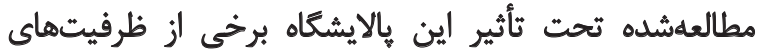

اكولوزيكى خود را از دست داده است ائير (جدول شماره • (1).

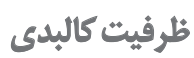

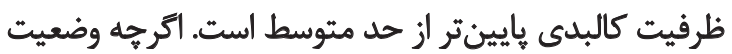

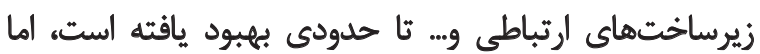

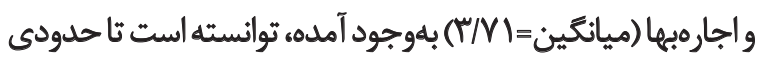

بهلت وجود نابرابرى و ضايعشدن حقوق ساكنان محلى سطح

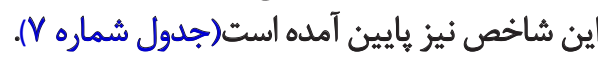

$$
\text { ظرفيث انسانى }
$$

ظرفيت انساني كمتر از حد متوسط است و بيش از همه عوامل،

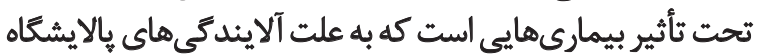

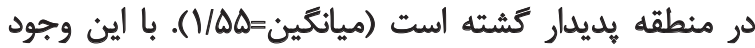

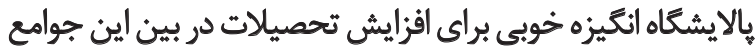

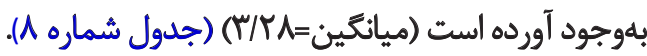

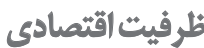

وضعيت اقتصادى منطقه تحت تأثير بالايشكاه كمتر از سطح

\begin{tabular}{|c|c|c|c|c|c|c|}
\hline \multicolumn{2}{|c|}{ قوى } & \multicolumn{2}{|c|}{ متوسط } & \multicolumn{2}{|c|}{ ضعيف } & \multirow{2}{*}{ ابعاد توانمندى } \\
\hline درصد & تعداد & درصد & تعداد & درصد & تعداد & \\
\hline $14 \%$ & 98 & $\Delta \mathrm{A} \%$ & ril & $r f \%$ & $N$ & ظرفيت اجتماعى \\
\hline$r+\%$ & $n^{*}$ & $p q \%$ & iva & $\mu \%$ & IIf & ظرفيت انسانى \\
\hline$\pi \%$ & A. & $p q / \Delta \%$ & MT & TNA\% & 1.0 & ظرفيت اقتصادى \\
\hline$\cdot 11 \%$ & $r$ & $1 v \%$ & 81 & $\Delta r \%$ & rq. & ظرفيت اكولوزيكى \\
\hline $10 \%$ & $\Delta r$ & rq\% & 1.1 & $\Delta \% \%$ & $r \cdot \Delta$ & ظرفيت كالبدى \\
\hline $.10 \%$ & r & wr $\%$ & er & $\Delta T / \Delta \%$ & $r \cdot r$ & ساختار فرصتها \\
\hline$v / 8 \%$ & rV & $\Delta T / F \%$ & ur & $r+\Lambda \%$ & Ifr & توانمندى \\
\hline
\end{tabular}

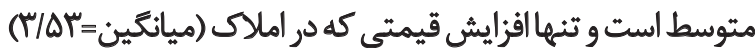
جدول fا. وضعيت ابعاد توانمئدى. 
جدول ها. نتايج آزمون فريدمن درباره رتبلبندى ابعاد توائمندى.

\begin{tabular}{|c|c|}
\hline مياتكين رتبه & ابعاد توانمندى \\
\hline P/MT & ظطرفيت اجتماعي \\
\hline$P / T r$ & ظُرفيت اقتصادى \\
\hline$F / 10$ & ظرفيت انسائى \\
\hline ( & ظرفيت كالبدى \\
\hline T/PA & ظرفِيت اكولوزيكي \\
\hline$r / R T$ & ساختار فرصتها \\
\hline
\end{tabular}

\section{تحمبن}

بسيارزيادى دارد. يس مئ بـوان بيان كرد احداث و بهرهبردارى از

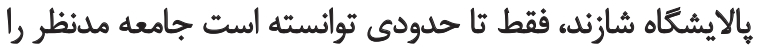

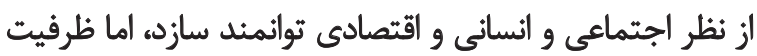

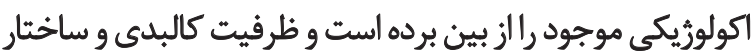
فرصتها نيز وضعيت مساعدى ندارند (جدول شماره f ()).

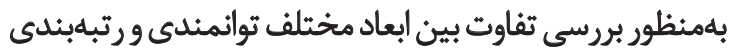

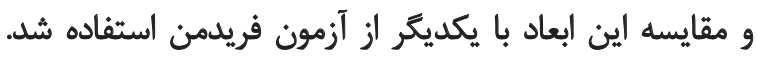

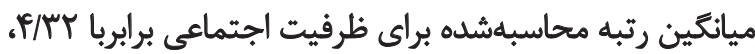

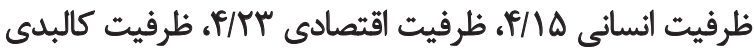

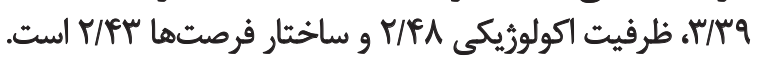

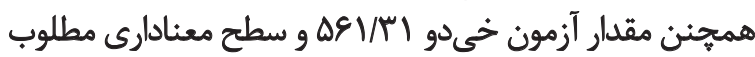

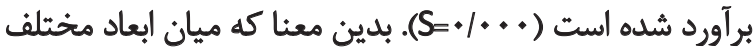

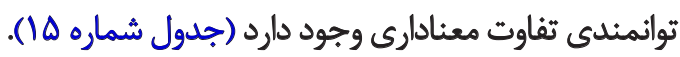

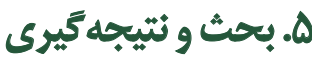

بدونشك آغاز يرورههاى توسعهاى در شهرستان شازند سطح

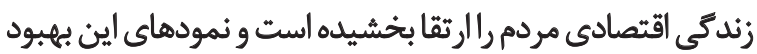

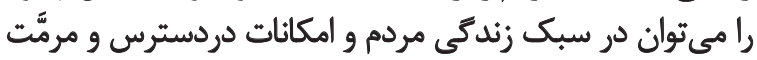

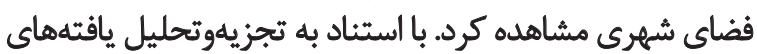

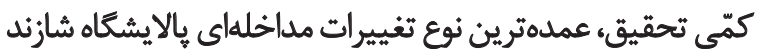

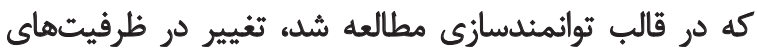

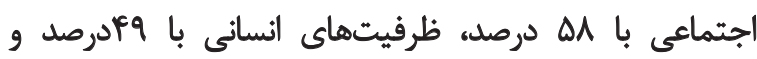

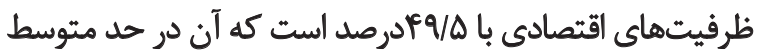

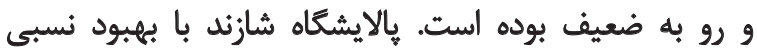

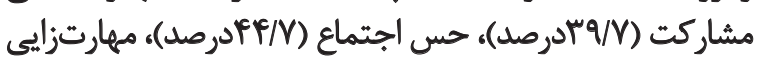

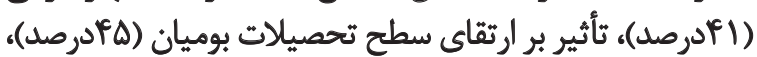

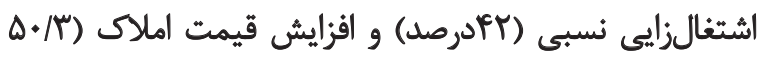

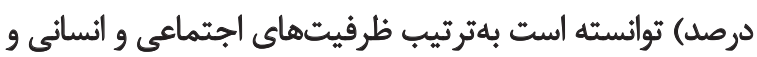
اقتصادى رادر حد كمى بهبود بخشد.

در ديخر ابعاد كالبدى و اكولوزيكى و ساختار فرصتها عملكرد
خدمات وضعيت نامساعدى دارد (جدول شماره (1).

$$
\text { ساختّار فرصتها }
$$

ساختار فرصتها نيز وضعيت مطلوبى ندارد و وايينتر از حد

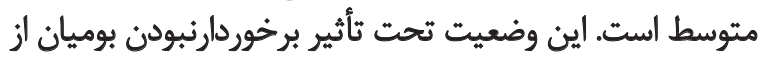

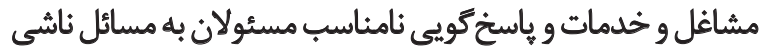

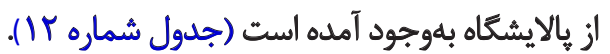

تا اينجا معرفهاى توانمندى توصيف شدند. حال براى بروسى إنى

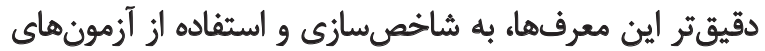

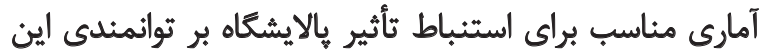

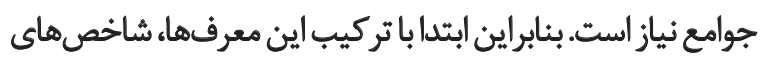
آن ساخته و سيس آزمون و مقايسه شدند.

$$
\text { آز مون هاى آمارى و مقايسه ميانكينهنا }
$$

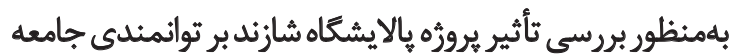

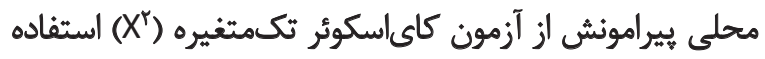

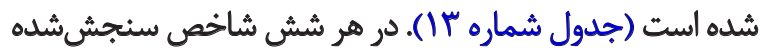

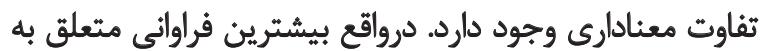

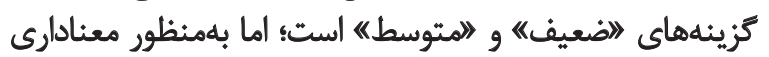

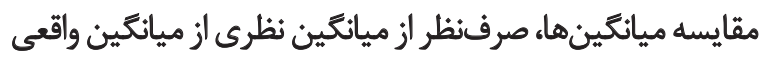

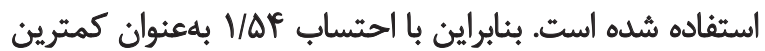

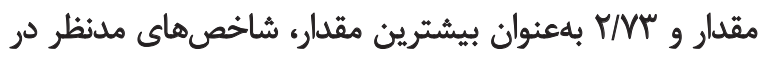

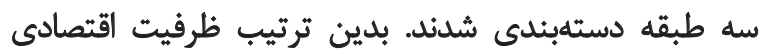

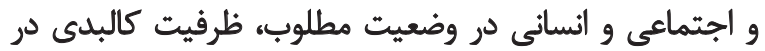

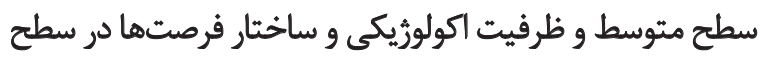
نامطلوب وضعيفى قرار كرفتند.

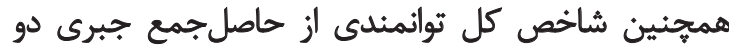

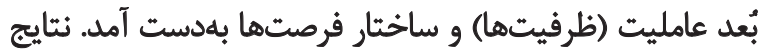

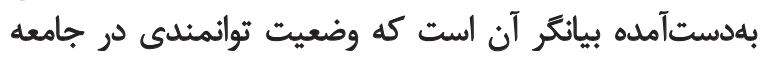
مطالعاتى متوسط و رو به بايين است و تا وضعيت مطلوب إن فاصله 


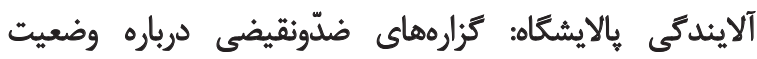

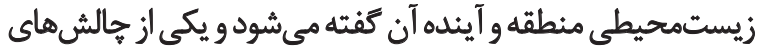

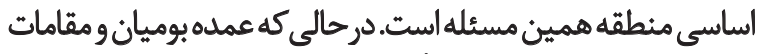

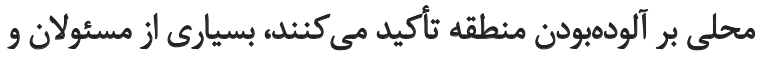

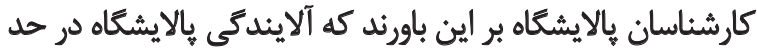

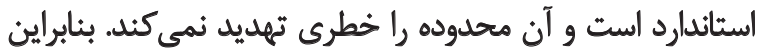

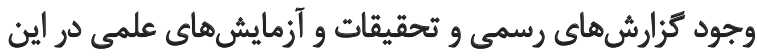

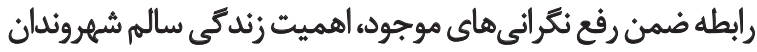
ساكن در منطقه را براى مسئولان متذكر مي شودود.

$$
\text { تشكر وقدردانى }
$$

اين مقاله از هايان نامه كارشناسى ارشد خانم معصومه دهقانى در

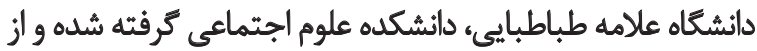

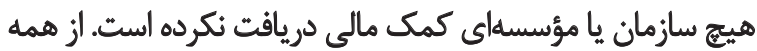

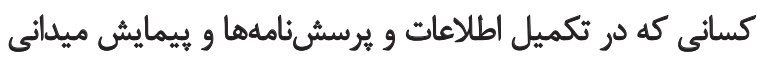

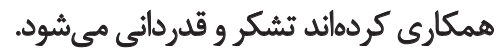

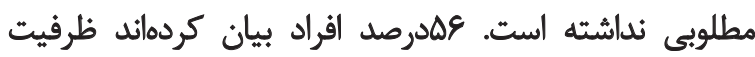

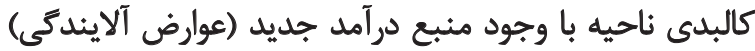

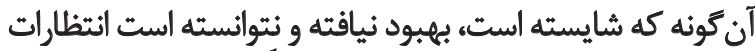

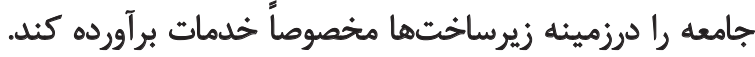

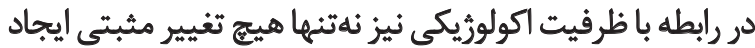

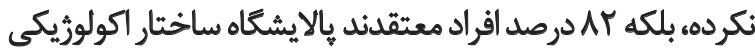

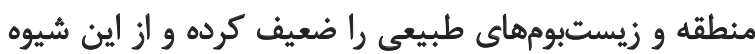

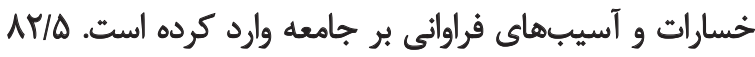

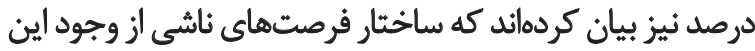

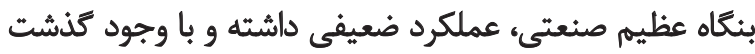

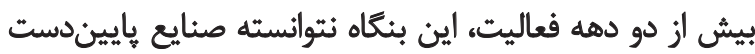

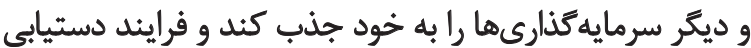

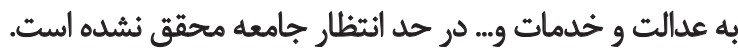

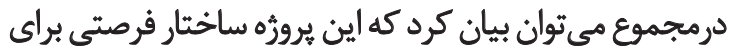

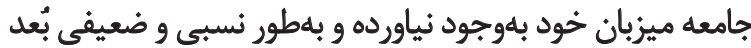

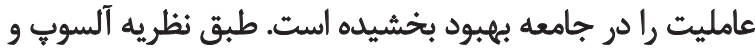

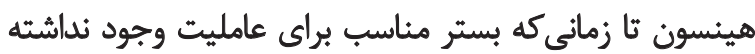

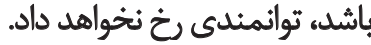

$$
\text { بيشنهادات }
$$

براي حل مسائل و جالشهاي بلوجودآمده بر اثر يالايشعاه و

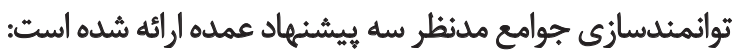
احداث و تقويت صنايع بايين دستج": با راهاندازي صنايع

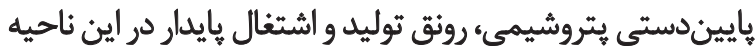

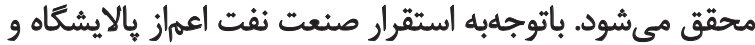

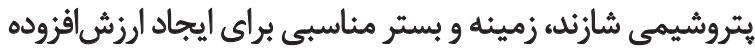

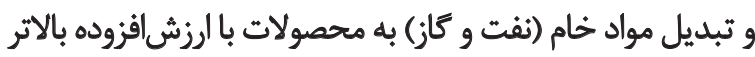
درست شده است. بنابراين با برنامهريزى منسجم واندم و واقع ترايانه

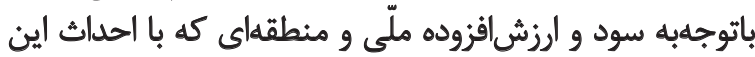

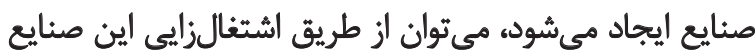

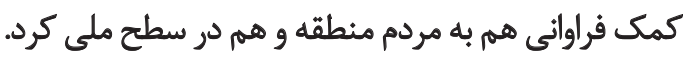

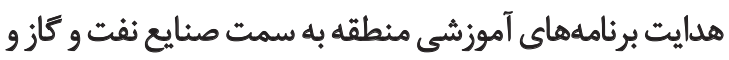

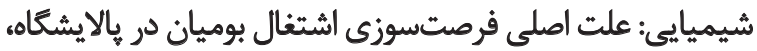

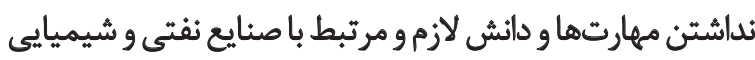

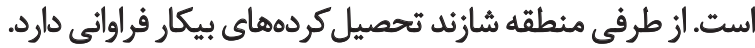

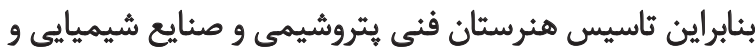

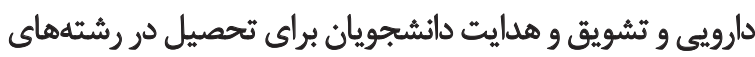

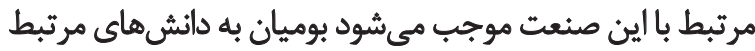

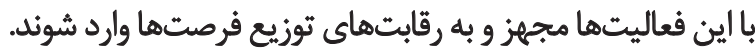
كارشناسىهاى زيستمحيطى در رابطه با ثأثيرات مخرب

9. صنايع پاييندست در صنعت نفت عبارتى است كه معمولاً براى اشاره به تصفيه

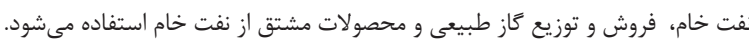




\section{References}

Alsop, R., \& Heinsohn, N. (2005). Measuring empowerment in practice: Structuring analysis and framing indicators. World Bank policy research working paper: N0. 3510. Washington, D. C.: World Bank Publications. Retrieved from https://openknowledge.worldbank.org/handle/10986/8856

Caffrey, P. (2002). An independent environmental and social assessment of the Camisea Gas Project (Unpublished report). Retrieved from http://amwt.ch/625

Erstad, M. (1997), Empowerment and organizational change. International Journal of Contemporary Hospitality Management, 9(7), 325-33.

Freire, P. (1970). Pedagogy of the oppressed [M. Bergman Ramos (English trans.)]. New York: Continuum.

Fundación para las Relaciones Internacionales y el Diálogo Exterior. (2006). Empowerment: Development backgrounder. Madrid: Fundación para las Relaciones Internacionales y el Diálogo Exterior. Retrieved from fride.org/descarga/BGR_Empowerment_ENG_ may06.pdf

Harrison, R. (1993). Human resource management: Issues and strategies. Boston: Addision Wesley Publication.

Heidari Sareban, V. (2012). [Empowerment a major step towards the rural development (Persian)]. Journal of Geographical Studies, 27(3), $169-88$.

Kabeer, N. (2005). Gender equality and women's empowerment: A critical analysis of the third millennium development goal1. Gender \& Development, 13(1), 13-24. doi: 10.1080/13552070512331332273

Khani, F. (2006). [The geography of development in the world and Iran (Persian)]. Tehran: Ghomes Publication.

Khayyati, M., \& Aazami, M. (2014). [Analysis of rural economic empowerment and its determinants (Case study: Rice producers in Rasht county) (Persian)]. Journal of Research and Rural Planning, $3(1), 56-44$.

Luttrell, C., Quiroz, S., Scrutton, C., \& Bird, K. (2009). Understanding and operationalising empowerment. London: Overseas Development Institute.

Mason, K. O., \& Smith, H. L. (2000). Husbands' versus wives' fertility goals and use of contraception: The influence of gender context in five Asian countries. Demography, 37(3), 299-311. doi: $10.2307 / 2648043$

McCall, T. (2003). Institutional design for community economic development models: Issues of opportunity and capacity. Community Development Journal, 38(2), 96-108. doi: 10.1093/cdj/38.2.96

Mirzaie, H., Ghaffari, Gh. R., \& Karimi, A. (2011). [The study of impact of industrialization and background variables on empowerment (Case study: Rural area of county of Qorveh) (Persian)]. Journal of Rural Research, 1(4), 99-128.

Motiee Langroodi, S. H., \& Najafi Kani, A. A. (2006). [Review and evaluate the effects of towns on rural settlements: The case of Babol county (Persian)]. Journal of Geographical Studies, 38(58), 14765.

Narayan-Parker, D. (2002). Empowerment and poverty reduction: A sourcebook. Washington, D. C.: World Bank Publications.
Peeters, L. W., J., \& Ateljevic, I. (2009). Women empowerment entrepreneurship nexus in tourism: Processes of social innovation. In J. Ateljevic, S. J. Page (Eds.). Tourism and entrepreneurship: International perspectives (pp. 75-90). Oxford : Butterworth-Heinemann.

Rahmani, M. (2007). [Micro-credits as empowering women: A case study of Posht-Rüd Village, Bam (Persian)] (MA thesis). Isfahan: University of Isfahan.

Rezvani, M. R., Ramezanzadeh Lasbouie, M., \& Mohammadpour, Jaberi, M. (2010). [The analysis of socio-economic effects of industrial areas on developing rural areas (Case study: Industrial area of Soleiman Abad, Tonekabon) (Persian)]. Geography and Development, 8(18), 5-26.

Sen, G. (1997). Empowerment as an approach to poverty: Background paper to human development report. Madrid: Instituto de Estudios del Hambre. Retrieved from http://www.ieham.org/html/docs/ Empowerment_as_an_approach_to_Poverty.pdf

Shaterian, M., \& Ganjipour, M. (2011). [Effects of civil investments in empowerment of rural areas (Case study: Abouzeid-Abad District) (Persian)]. Journal of Rural Research, 1(3), 131-52.

Talebian, S. A., \& Omrani Majd, A. (2008). [A survey of the social impacts of oil and gas projects (Persian)]. Journal of Human Resource Management in Oil Industry, 3(1), 102-22.

Thomas, K. W., \& Velthouse, B. A. (1990). Cognitive elements of empowerment: An "interpretive" model of intrinsic task motivation. Academy of Management Review, 15(4), 666-81. doi: 10.5465/ amr.1990.4310926

Verity, F. (2007). Community capacity building: A review of the literature. Adelaide: Department of Health Press.

Wallerstein, N. (2002). Empowerment to reduce health disparities. Scandinavian Journal of Public Health, 30(59), 72-77. doi: $10.1177 / 14034948020300031201$

Zahedi, M. J. (2008 July 14). [Strengthening and delegated legislative power to the people (Persian)]. Etemad Newspaper, 4. 